ARTICLE

\title{
Spectroscopic and computational investigation of actinium coordination chemistry
}

Maryline G. Ferrier ${ }^{1}$, Enrique R. Batista ${ }^{1}$, John M. Berg${ }^{1}$, Eva R. Birnbaum¹, Justin N. Cross ${ }^{1}$, Jonathan W. Engle ${ }^{1}$, Henry S. La Pierre ${ }^{1}$, Stosh A. Kozimor ${ }^{1}$, Juan S. Lezama Pacheco², Benjamin W. Stein ${ }^{1}$, S. Chantal E. Stieber ${ }^{1,3}$ \& Justin J. Wilson ${ }^{1,4}$

Actinium-225 is a promising isotope for targeted- $\alpha$ therapy. Unfortunately, progress in developing chelators for medicinal applications has been hindered by a limited understanding of actinium chemistry. This knowledge gap is primarily associated with handling actinium, as it is highly radioactive and in short supply. Hence, Ac ${ }^{\text {III }}$ reactivity is often inferred from the lanthanides and minor actinides (that is, Am, Cm), with limited success. Here we overcome these challenges and characterize actinium in $\mathrm{HCl}$ solutions using $\mathrm{X}$-ray absorption spectroscopy and molecular dynamics density functional theory. The $\mathrm{Ac}-\mathrm{Cl}$ and $\mathrm{Ac}-\mathrm{O}_{\mathrm{H}_{2} \mathrm{O}}$ distances are measured to be 2.95(3) and 2.59(3) $\AA$, respectively. The $X$-ray absorption spectroscopy comparisons between $A c^{\prime \prime \prime}$ and $\mathrm{Am}^{\text {III }}$ in $\mathrm{HCl}$ solutions indicate $\mathrm{Ac} \mathrm{c}^{\text {III }}$ coordinates more inner-sphere $\mathrm{Cl}^{1-}$ ligands $(3.2 \pm 1.1)$ than $\mathrm{Am}^{\mathrm{III}}(0.8 \pm 0.3)$. These results imply diverse reactivity for the +3 actinides and highlight the unexpected and unique $A c^{\prime \prime I}$ chemical behaviour.

\footnotetext{
${ }^{1}$ Los Alamos National Laboratory, Los Alamos, New Mexico 87545, USA. ${ }^{2}$ Stanford University, Stanford, California 94305, USA. ${ }^{3}$ California State Polytechnic University, Pomona, California 91768, USA. ${ }^{4}$ Cornell University, Ithaca, New York 14853, USA. Correspondence and requests for materials should be addressed to E.R.B. (email: erb@lanl.gov) or to S.A.K. (email: stosh@lanl.gov).
} 
U nderstanding of the chemistry of trivalent actinides has broad-potential impacts on society through diverse areas, including cancer therapy ${ }^{1-3}$, nuclear waste ${ }^{4-6}$, energy and global security ${ }^{7}$. However, with the exception of $\mathrm{U}^{\mathrm{III}}$ (refs 6-9), fundamental understanding of the early-tomid-actinides in the trivalent oxidation state $\left(\mathrm{An}=\mathrm{Ac}^{\mathrm{III}}, \mathrm{Np}^{\mathrm{III}}\right.$, $\mathrm{Pu}^{\mathrm{III}}, \mathrm{Am}^{\mathrm{III}}, \mathrm{Cm}^{\mathrm{III}}, \mathrm{Bk}^{\mathrm{III}}$ and $\mathrm{Cf}^{\mathrm{III}}$ ) remains substantially less developed than that of the main group, transition metals and lanthanides. Significant experimental challenges associated with the highly radioactive samples, limited access to material of interest, and the redox instability of some $\mathrm{An}^{\mathrm{III}}$ ions have necessitated numerous heroic efforts to advance $\mathrm{An}^{\mathrm{III}}$ chemistry $6,10-15$

The 2015 Long Range Plan for the DOE-NP Isotope Program ${ }^{16}$ highlighted the importance of advancing $A c^{\mathrm{III}}$ chemistry in comparison with the other $\mathrm{An}^{\mathrm{III}}$ ions. In this document, ${ }^{225} \mathrm{Ac}$ was identified as a promising anticancer therapeutic agent. The report focused on global interest in exploiting the $\alpha$-emissions from ${ }^{225} \mathrm{Ac}$ and its radioactive daughters to selectively destroy the malignant cells ${ }^{17,18}$. To use these $\alpha$-particles therapeutically, the ${ }^{225} \mathrm{Ac}$ isotope must be attached to cancer-selective targeting vectors using a stable chelating agent. Unfortunately, the limited availability of ${ }^{225} \mathrm{Ac}$ $\left[\mathrm{t}_{1 / 2}=10.0(1) \mathrm{d}\right.$; National Nuclear Data Center (NNDC) $]$, or a useful surrogate, has impeded development of actinium chelators. For instance, the use of ${ }^{227} \mathrm{Ac}$, the longest-lived actinium isotope $\left[\mathrm{t}_{1 / 2}=21.772(3) \mathrm{y}\right.$; NNDC] provides the best possible alternative for improving ligand design. However, the worldwide inventory of ${ }^{227} \mathrm{Ac}$ is currently insufficient for meeting this demand. Historically, these challenges were magnified by the electronic ground state of $A c^{I I I}\left(5 f^{0} 6 d^{0}\right)$, which is essentially invisible to common spectroscopies (for example, ultraviolet-visible, fluorescence, electron paramagnetic resonance and so on). Hence, applying alternative characterization methods that account for (1) high radioactivity, (2) small samples sizes (1-30 $\mu \mathrm{g})$ and (3) closed shell electronic configurations would facilitate innovative chelation designs for delivery of ${ }^{225} \mathrm{Ac}$ through the biological milieu to the targeted tumour site.

Recent upgrades at the Stanford Synchrotron Radiation Lightsource (SSRL), such as the new 100-element solid-state Ge detector array on beamline 11-2, have provided new opportunities to overcome the aforementioned challenges. This capability has improved sensitivity for trace-level detection in environmental samples using X-ray absorption fine-structure (XAFS) spectroscopy ${ }^{19,20}$. While this instrumentation has been used primarily in environmental sciences, here we exploit the capability to conduct the first actinium XAFS study reported to date. Using this method, ${ }^{227} \mathrm{Ac}$ in concentrated $\mathrm{HCl}$ solutions are characterized at the $\mathrm{Ac}_{3}$-edge. Our interpretations of the spectra are guided by molecular dynamics density functional theory (MD-DFT) calculations ${ }^{21-25}$. To establish confidence in the spectroscopic and computational methods, the $A c^{\text {III }}$ results are compared with analogous measurements on Am ${ }^{\mathrm{III}}$. This ion is selected because-among the redox stable trivalent actinides-its ionic radius is most similar to Ac ${ }^{\text {III }}$. Overall, this approach enables the $\mathrm{Ac}-\mathrm{Cl}$ and $\mathrm{Ac}-\mathrm{O}_{\mathrm{H}_{2} \mathrm{O}}$ distances to be measured and allows the coordination chemistry of $A c^{I I I}$ and $A m^{I I I}$ to be directly compared. The experimental and computational data show more chloride ions in the inner coordination sphere for $\mathrm{Ac}$ III and the results are presented in comparison with previous actinide(III) XAFS studies. This study reveals an unexpected divergence in $+3 f$-element reactivity. Furthermore, the research highlights the need to better characterize $\mathrm{An}^{\mathrm{III}}$ chemistry in support of developing $\alpha$ emitting therapeutic agents.

\section{Results}

$\mathrm{X}$-ray absorption near-edge structure spectroscopy. To evaluate $\mathrm{Ac}^{\mathrm{III}}$ and $\mathrm{Am}^{\mathrm{III}}$ binding of $\mathrm{Cl}^{1-}$ versus $\mathrm{H}_{2} \mathrm{O}$, three solution-phase samples were prepared: actinium chloride ( $\mathrm{Ac}^{\mathrm{III}}$ in $\left.\mathrm{HCl} ; 11 \mathrm{M}\right)$; americium chloride $\left(\mathrm{Am}^{\mathrm{III}}\right.$ in $\left.\mathrm{HCl} ; 11 \mathrm{M}\right)$; and the americium aquo ion $\left(\mathrm{Am}^{\mathrm{III}}\right.$ in $\left.\mathrm{HO}_{3} \mathrm{SCF}_{3}, 0.11 \mathrm{M}\right)$, referred to hereafter as $\mathbf{A c}-\mathbf{H C l}, \mathbf{A m}-\mathbf{H C l}$ and $\mathbf{A m}$-Aquo. To mitigate safety concerns associated with the ${ }^{227} \mathrm{Ac}$ isotope, radioactive daughters (primarily ${ }^{227} \mathrm{Th}$ and ${ }^{223} \mathrm{Ra}$ ) were removed before the measurements at the SSRL synchrotron, as previously described (see Methods) ${ }^{26,27}$. The samples were then returned to Los Alamos National Laboratory before a significant quantity of the daughters re-emerged ( $\sim 10$ days). The Ac and $\mathrm{Am} \mathrm{L}_{3}$-edge $\mathrm{X}$-ray absorption near-edge structure (XANES) spectra from $\mathbf{A c}-\mathbf{H C l}$, $\boldsymbol{A} \boldsymbol{m}-\mathbf{H C l}$ and $\boldsymbol{A m}$-Aquo were background subtracted and normalized (Fig. 1). The spectra were similar as they contained a pronounced edge-peak superimposed on an absorption threshold. From the perspective of the free ion, the edge-feature could be crudely described as originating from electric-dipole allowed transitions from the actinide $2 p$-orbitals to unoccupied states that contain actinide $6 d$-character, that is, for $\mathrm{Ac}^{\mathrm{III}}$ $2 p^{6} \ldots 5 f^{0} 6 d^{0} \rightarrow 2 \mathrm{p}^{5} \ldots 5 f^{0} 6 d^{1}$ (refs 28,29 ).

The Ac $\mathrm{L}_{3}$-edge spectrum was of quintessential significance, as it represented the first actinium XANES measurement. The edgepeak line shape was quite broad and spanned over $\sim 30 \mathrm{eV}$, owing to the short core-hole lifetime. The peak maximum and inflection point (where first and second derivatives of the data equalled zero) were determined to be $15,877.3$ and $15,873.9 \mathrm{eV}$, respectively. For the americium samples, the inflection point from Am-Aquo was found at $18,514.3 \mathrm{eV}$, which was consistent with americium in the +3 oxidation state ${ }^{30,31}$. Changing the solution matrix from $\mathrm{HO}_{3} \mathrm{SCF}_{3}(0.11 \mathrm{M})$ to $\mathrm{HCl}(11 \mathrm{M})$ shifted the edgepeak inflection point to lower energy by $0.7 \mathrm{eV}$. The $\mathrm{Am}_{3}$-edge energy difference was attributed to an electronic change that accompanied $\mathrm{Cl}^{1-}$ displacement of $\mathrm{H}_{2} \mathrm{O}$ in the $\mathrm{Am}^{\mathrm{IIP}}$ inner coordination sphere (vide infra), that is, $\boldsymbol{A m}$-Aquo versus Am-HCl. Given the relative ease with which the Ac ${ }^{\mathrm{III}}$ and $\mathrm{Am}^{\mathrm{III}} \mathrm{L}_{3}$-edge XANES measurements were obtained-and in light of the incompatibility of other spectroscopic techniques for

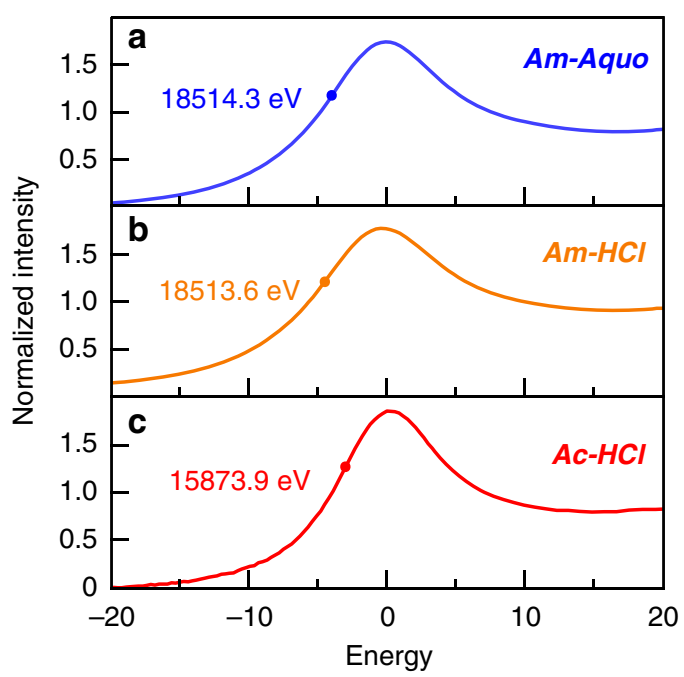

Figure 1 | Solution phase $\mathbf{A} \mathbf{c}^{\mathbf{\prime \prime \prime}}$ and $\mathbf{A m} \mathbf{m}^{\text {III }} \mathbf{L}_{\mathbf{3}}$-edge XANES. (a) XANES spectra for Am-Aquo $\left(0.11 \mathrm{M} \mathrm{HO}_{3} \mathrm{SCF}_{3}\right.$ ) in blue trace. (b) XANES spectra for $\mathbf{A m}-\mathbf{H C l}(11 \mathrm{M} \mathrm{HCl})$ in orange trace. (c) XANES spectra for $\mathbf{A c}-\mathbf{H C l}$ $(11 \mathrm{M} \mathrm{HCl})$ in red trace. The actinium and americium spectra were calibrated in situ to $\mathrm{RbCl}$ pellet $(15,203.81 \mathrm{eV})$ and $\mathrm{Zr}$ foil $(17,998 \mathrm{eV})$ respectively. 
probing dilute actinium samples-we anticipate that these results will provide a foundation for characterizing the coordination chemistry of actinium in other chemical environments in the future.

Extended X-ray absorption fine structure. Appreciable differences were observed in the solution-phase $k^{3} \chi(k)$ extended X-ray absorption fine-structure (EXAFS) data (room temperature) from solutions containing $\mathbf{A c}-\mathbf{H C l}, \mathbf{A m}-\mathbf{H C l}$ and $\boldsymbol{A} \boldsymbol{m}$-Aquo (Fig. 2). For instance, a substantial phase shift and change in frequency in the EXAFS oscillations was observed in the spectrum from $\mathbf{A c} \mathbf{H C l}$ in comparison with the americium spectra. The $\mathbf{A c}-\mathbf{H C l}$ spectrum was comprised of at least two substantial contributions; one characterized by a long frequency and the other by a short frequency. The presence of two frequencies was most likely associated with a significant number of both $\mathrm{Cl}^{1-}$ and $\mathrm{H}_{2} \mathrm{O}$ molecules in the $\mathrm{Ac}^{\mathrm{III}}$ inner coordination sphere. In contrast, for $\mathbf{A m}-\mathbf{H C l}$, the frequency of EXAFS oscillations was dominated by one major sinusoidal component, such that the $\boldsymbol{A m}-\mathbf{H C l}$ spectrum was almost superimposable on that from Am-Aquo. The similarity between $\mathbf{A m}-\mathbf{H C l}$ and Am-Aquo suggested that $\mathrm{H}_{2} \mathrm{O}$ molecules dominated the inner coordination sphere in $\mathbf{A m}-\mathbf{H C l}$, with $\mathrm{Cl}^{1-}$ content being slight. Overall, this comparison highlighted significant differences in $\mathrm{Ac}^{\mathrm{III}}$ versus $\mathrm{Am}^{\mathrm{III}}$ solution speciation.

The EXAFS data were fit by allowing the coordination numbers $(\mathrm{CN})$, the Debye-Waller factors $\left(\sigma^{2}\right)$, and the interatomic distances $(R)$ to converge to reasonable values. Limitations associated with the solution-phase room-temperature EXAFS measurements constrained meaningful data to $\sim 10 k(9,10.5$ and $12 \mathrm{k}$ for solutions containing $\mathbf{A c}-\mathbf{H C l}, \mathbf{A m}-\mathbf{H C l}$ and $\mathbf{A m}-\mathbf{A q u o}$, respectively). As a result, scattering pathways beyond the first coordination shell (including multiple scattering pathways, for example, $\mathrm{Cl}-\mathrm{M}-\mathrm{H}_{2} \mathrm{O}$ ) were not considered. To most effectively describe how the EXAFS models were obtained, it was instructive to begin with $\boldsymbol{A m}$-Aquo, then introduce the possibility of $\mathrm{Cl}^{1-}$ ligation for $\mathbf{A m}-\mathbf{H C l}$, and conclude with the $\mathbf{A c}-\mathbf{H C l}$.

Before modelling the EXAFS data from $\boldsymbol{A m}$-Aquo, we initially calculated (FEFF8 (ref. 32)) an EXAFS spectrum using

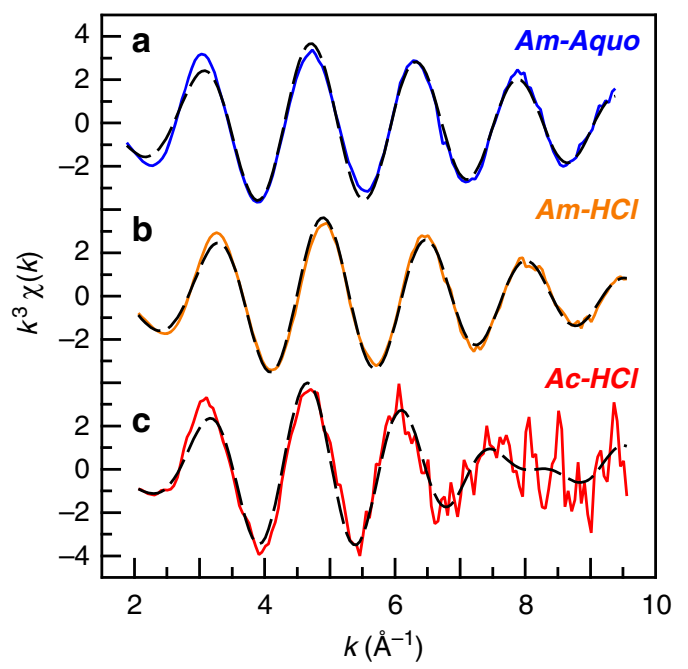

Figure 2 | Solution phase $\mathbf{A} c^{\text {III }}$ and $\mathbf{A m}^{\text {III }} \mathbf{L}_{\mathbf{3}}$-edge EXAFS. (a) EXAFS $k^{3} \chi(k)$ spectra for $\boldsymbol{A m}$-Aquo $\left(0.11 \mathrm{M} \mathrm{HO}_{3} \mathrm{SCF}_{3}\right)$ in blue trace. (b) EXAFS $k^{3} \chi(k)$ spectra for $\boldsymbol{A m}-\boldsymbol{H C l}(11 \mathrm{M} \mathrm{HCl})$ in orange trace. (b) EXAFS $k^{3} \chi(k)$ spectra for $\mathbf{A c}-\mathbf{H C l}(11 \mathrm{M} \mathrm{HCl})$ in red trace. Fits to the data have been provided as dashed black traces. atomic coordinates obtained from the $\left[\mathrm{Am}\left(\mathrm{H}_{2} \mathrm{O}\right)_{9}\right]\left[\mathrm{O}_{3} \mathrm{SCF}_{3}\right]_{3}$ single-crystal X-ray diffraction data, previously reported ${ }^{33}$. The calculated EXAFS spectrum was composed of two main scattering pathways. The first path originated from six oxygen atoms with an $\mathrm{Am}-\mathrm{O}_{\mathrm{H}_{2} \mathrm{O}}$ distance of $2.465 \AA$ and the second path had three oxygen atoms at $2.578 \AA$. Although various EXAFS fitting parameters were considered based on these calculations, only one oxygen shell could be resolved in the experimental data, as our resolution between $k$ of 2.6 and 12 was only $0.167 \AA(\pi / 2 \Delta k)$. The final model of the EXAFS data with the lowest residual factor and reduced chi-squared value consisted of $9.5 \pm 0.9$ oxygen atoms at 2.48(1) $\AA$ (Table 1 and Figs 2 and 3 ). These $\mathrm{Am}-\mathrm{O}_{\mathrm{H}_{2} \mathrm{O}}$ bond distances and $\mathrm{CNs}$ were consistent with the $\mathrm{Am}\left(\mathrm{H}_{2} \mathrm{O}\right)_{9}^{3}{ }^{+}$solid-state structure and EXAFS spectra previously obtained on $\mathrm{Am}^{\mathrm{III}}$ aquo ions in different solvent matrices, for example, Stumpf et al. ${ }^{34}$ in $0.025 \mathrm{M} \mathrm{HClO}_{4}$ and Allen et al. $^{35}$ in $0.25 \mathrm{M} \mathrm{HCl}$ (Table 1).

The EXAFS fitting results can be interpreted using static or dynamic descriptions. A static interpretation suggested that the americium aquo ion had $9.5 \mathrm{H}_{2} \mathrm{O}$ ligands held at a fixed 2.48(1) distance. In contrast, the dynamic interpretation described the EXAFS data as an averaged spectrum from a heterogeneous mixture over the lifetime of the experiment. In this scenario, the number of $\mathrm{H}_{2} \mathrm{O}$ molecules in the $\mathrm{Am}^{\mathrm{III}}$ inner coordination sphere varied, as did the $\mathrm{Am}-\mathrm{O}_{\mathrm{H}_{2} \mathrm{O}}$ distances. To provide insight, MD-DFT calculations were carried out on a single $\mathrm{Am}^{\mathrm{III}}$ ion inside a box $\left(12.54 \times 12.45 \times 12.68 \AA^{3}\right)$ of explicit $\mathrm{H}_{2} \mathrm{O}(64$ total $)$ solvent molecules. Before the simulation, the components of the box were randomized (see Methods), and then the MD were modelled for $330 \mathrm{fs}$. The MD trajectory showed a time average of $8.1 \pm 0.3 \mathrm{H}_{2} \mathrm{O}$ molecules within a $4 \AA$ radius of the $\mathrm{Am}^{\mathrm{III}}$ ion. The average $\mathrm{Am}-\mathrm{O}_{\mathrm{H}_{2} \mathrm{O}}$ distances were displayed by the red solid traces in Fig. 4. At the start of the calculations the variation in Am$\mathrm{O}_{\mathrm{H}_{2} \mathrm{O}}$ bond distances were large, ranging from 2.7 to $2.5 \AA$. However, after $\sim 50 \mathrm{fs}$, the magnitude of these oscillations became smaller and centred $\sim 2.5 \AA$. In general, these calculations were in excellent agreement with the EXAFS experiment. Both theory and experiment identified a $\mathrm{CN}$ around nine and the calculated average $\mathrm{Am}-\mathrm{O}_{\mathrm{H}_{2} \mathrm{O}}$ distances bracketed the experimental value (red dashed trace). The good agreement of the Am-Aquo experimental and computational EXAFS analyses with the single-crystal and solution-phase EXAFS studies provided confidence and credibility that our methods could be applied accurately to other actinide systems.

To obtain atomic coordinates for modelling the $\mathbf{A m}-\mathbf{H C l}$ data, we calculated EXAFS spectra using FEFF8 from two different sources. The first model employed atomic coordinates from previously reported $\left[\mathrm{AmCl}_{2}\left(\mathrm{H}_{2} \mathrm{O}\right)_{6}\right] \mathrm{Cl}$ single-crystal X-ray diffraction data ${ }^{36}$, which had two $\mathrm{Cl}^{1-}$ and six $\mathrm{H}_{2} \mathrm{O}$ inner-sphere ligands. The second simulation utilized a DFT-optimized structure of $\mathrm{AmCl}_{2}\left(\mathrm{H}_{2} \mathrm{O}\right)_{4}^{1+}$. Refinement of the experimental EXAFS data using fitting parameters from either model converged to the same point (Table 1 and Figs 2 and 3), showing an approximate nine-coordinate $\mathrm{Am}^{\mathrm{III}}$ ion with $0.8 \pm 0.3 \mathrm{Cl}^{1-}$ and $8.3 \pm 0.9 \mathrm{H}_{2} \mathrm{O}$ molecules in the inner sphere. Although the contributions from $\mathrm{Cl}^{1-}$ to the overall EXAFS spectrum seemed slight (Fig. 3), omitting the $\mathrm{Cl}^{1-}$ shell provided a significantly worse model, by over $91 \%$ confidence as determined from the Hamilton statistical test $^{37}$. The measured americium coordination environment seemed reasonable when compared with other solution-phase EXAFS studies. For instance, our $\mathbf{A m}-\mathbf{H C l} \mathrm{CNs}-$ collected in $\mathrm{HCl}$ solutions of $11 \mathrm{M}$-were bracketed by those determined from solutions with lower and higher $\mathrm{Cl}^{1-}$ concentrations (Table 1). Allen et al.'s EXAFS experiments at lower $\mathrm{HCl}$ solutions $(0.25 \mathrm{M})$ showed no inner-sphere $\mathrm{Cl}^{1-}$ ligands, while those at higher $\mathrm{Cl}^{1-}$ concentrations-a mixture of $\mathrm{HCl}(0.25 \mathrm{M})$ and $\mathrm{LiCl}$ 
Table 1 | Structural parameters determined using solution-phase EXAFS.

\begin{tabular}{|c|c|c|c|c|c|c|}
\hline Compound & Matrix & Scattering path & CN & $R(\AA)$ & $\sigma^{2}\left(\AA^{2}\right)$ & $\Delta E_{0}(e V)$ \\
\hline \multirow[t]{2}{*}{$\mathrm{Ac}-\mathrm{HCl}$} & $\mathrm{HCl}(11 \mathrm{M})$ & $A c-O_{\mathrm{H}_{2} \mathrm{O}}$ & $6.6 \pm 1.8$ & $2.59(3)$ & 0.0074 & -4.29 \\
\hline & & $\mathrm{Ac}-\mathrm{Cl}$ & $3.2 \pm 1.1$ & 2.95(3) & 0.0074 & \\
\hline $\mathrm{U}^{\mathrm{III}}\left(\mathrm{H}_{2} \mathrm{O}\right)_{y}$ (ref. 56) & $\mathrm{pH} \mathrm{O} \mathrm{HCl}$ & $\mathrm{U}-\mathrm{O}_{\mathrm{H}_{2} \mathrm{O}}$ & $9.1 \pm 0.6$ & $2.52(1)$ & $0.009(1)$ & 12.8 \\
\hline $\mathrm{Pu}^{\mathrm{lll}}\left(\mathrm{H}_{2} \mathrm{O}\right)_{y}$ (ref. 35) & $\mathrm{LiCl}(0.01 \mathrm{M})$ & $\mathrm{Pu}-\mathrm{O}_{\mathrm{H}_{2} \mathrm{O}}$ & $9.2 \pm 0.33$ & $2.51(2)$ & 0.010 & -10.4 \\
\hline $\mathrm{Pu}^{\mathrm{III}}\left(\mathrm{H}_{2} \mathrm{O}\right)_{y}$ (ref. 56) & $\mathrm{pH} \mathrm{O} \mathrm{HCl}$ & $\mathrm{Pu}-\mathrm{O}_{\mathrm{H}_{2} \mathrm{O}}$ & $9.9 \pm 0.3$ & $2.49(1)$ & $0.009(1)$ & 7.0 \\
\hline $\mathrm{Pu}^{\prime \prime \prime}{ }_{\text {aq }}$ (ref. 57) & $\mathrm{HClO}_{4}(1 \mathrm{M})$ & $\mathrm{Pu}-\mathrm{O}_{\mathrm{H}_{2} \mathrm{O}}$ & $8.6 \pm 0.2$ & $2.50(2)$ & 0.0083 & 7.16 \\
\hline $\mathrm{Am}^{\mathrm{III}}\left(\mathrm{H}_{2} \mathrm{O}\right)_{x}^{3}+$ (ref. 35) & $\mathrm{HCl}(0.25 \mathrm{M})$ & $\mathrm{Am}-\mathrm{O}_{\mathrm{H}_{2} \mathrm{O}}$ & $10.3 \pm 0.33$ & $2.48(2)$ & 0.009 & -8.7 \\
\hline $\mathrm{Am}^{\mathrm{III}}\left(\mathrm{H}_{2} \mathrm{O}\right)_{x}^{3}+$ (ref. 58) & $\mathrm{NaClO}_{4}(0.03 \mathrm{M}, \mathrm{pH} 3.5)$ & $\mathrm{Am}-\mathrm{O}_{\mathrm{H}_{2} \mathrm{O}}$ & $9.0 \pm 0.0$ & $2.47(1)$ & $0.0074(5)$ & 7.2 \\
\hline \multirow[t]{2}{*}{$\mathrm{Am}-\mathrm{HCl}$} & $\mathrm{HCl}(11 \mathrm{M})$ & $\mathrm{Am}-\mathrm{O}_{\mathrm{H}_{2} \mathrm{O}}$ & $8.3 \pm 0.86$ & $2.48(1)$ & 0.0095 & -4.29 \\
\hline & & $\mathrm{Am}-\mathrm{Cl}$ & $0.8 \pm 0.3$ & $2.75(3)$ & 0.0095 & \\
\hline \multirow[t]{2}{*}{$\mathrm{Am}^{\mathrm{III}} \mathrm{Cl}_{x}\left(\mathrm{H}_{2} \mathrm{O}\right)_{x}$ (ref. 35) } & $\mathrm{HCl}(10 \mathrm{M} \mathrm{LiCl})$ & $\mathrm{Am}-\mathrm{O}_{\mathrm{H}_{2} \mathrm{O}}$ & $7.6 \pm 0.33$ & $2.48(2)$ & 0.009 & -7.3 \\
\hline & & $\mathrm{Am}-\mathrm{Cl}$ & $1.2 \pm 0.1$ & $2.80(6)$ & 0.005 & \\
\hline $\mathrm{Am}^{\mathrm{III}} \mathrm{Cl}_{x}\left(\mathrm{H}_{2} \mathrm{O}\right)_{x}$ (ref. 35) & $\mathrm{HCl}(12.5 \mathrm{M} \mathrm{LiCl})$ & $\mathrm{Am}-\mathrm{O}_{\mathrm{H}_{2} \mathrm{O}}$ & $6.4 \pm 0.33$ & $2.51(2)$ & 0.009 & -6.1 \\
\hline $\begin{array}{l}\mathrm{Cm}^{\mathrm{III}}\left(\mathrm{H}_{2} \mathrm{O}\right)_{y}(\text { ref. 12) } \\
\mathrm{Cm}^{\mathrm{III}} \mathrm{Cl}_{x}\left(\mathrm{H}_{2} \mathrm{O}\right)_{y}(\text { ref. 35) }\end{array}$ & & $\mathrm{Cm}-\mathrm{Cl}$ & $2.4 \pm \pm 0.1$ & $2.76(6)$ & 0.005 & \\
\hline $\mathrm{Bk}^{\mathrm{III}}\left(\mathrm{H}_{2} \mathrm{O}\right)_{y}$ (ref. 11) & $\mathrm{HClO}_{4}(1 \mathrm{M})$ & $\mathrm{Bk}-\mathrm{O}_{\mathrm{H}_{2} \mathrm{O}}$ & $9.0 \pm 0.6$ & $2.43(2)$ & $0.009(2)$ & 2.7 \\
\hline $\mathrm{Cf}^{\prime l l}\left(\mathrm{H}_{2} \mathrm{O}\right)_{y}$ (ref. 59) & $\mathrm{HClO}_{4}(0.1 \mathrm{M})$ & $\mathrm{Cf}-\mathrm{O}_{\mathrm{H}_{2} \mathrm{O}}$ & $8.0 \pm 0.0$ & $2.42(1)$ & $0.0077(1)$ & 1.76 \\
\hline $\mathrm{Cf}^{\prime l l}\left(\mathrm{H}_{2} \mathrm{O}\right)_{y}($ ref. 60) & $\mathrm{HCl}(1 \mathrm{M})$ & $\mathrm{Cf}-\mathrm{O}_{\mathrm{H}_{2} \mathrm{O}}$ & $8.5 \pm 1.5$ & $2.42(2)$ & $0.0095(1)$ & 1.4 \\
\hline
\end{tabular}

$\mathrm{CN}$, coordination number; EXAFS, extended X-ray absorption fine structure.

Comparison between data obtained in this study from $\mathbf{A m}-\mathbf{A q u o}, \mathbf{A m}-\mathbf{H C l}$ and $\mathbf{A c}-\mathbf{H C l}$ with previously reported $\mathrm{An}{ }^{I I I}$ aquo and chloride complexes.

Data shown in bold are from this study.

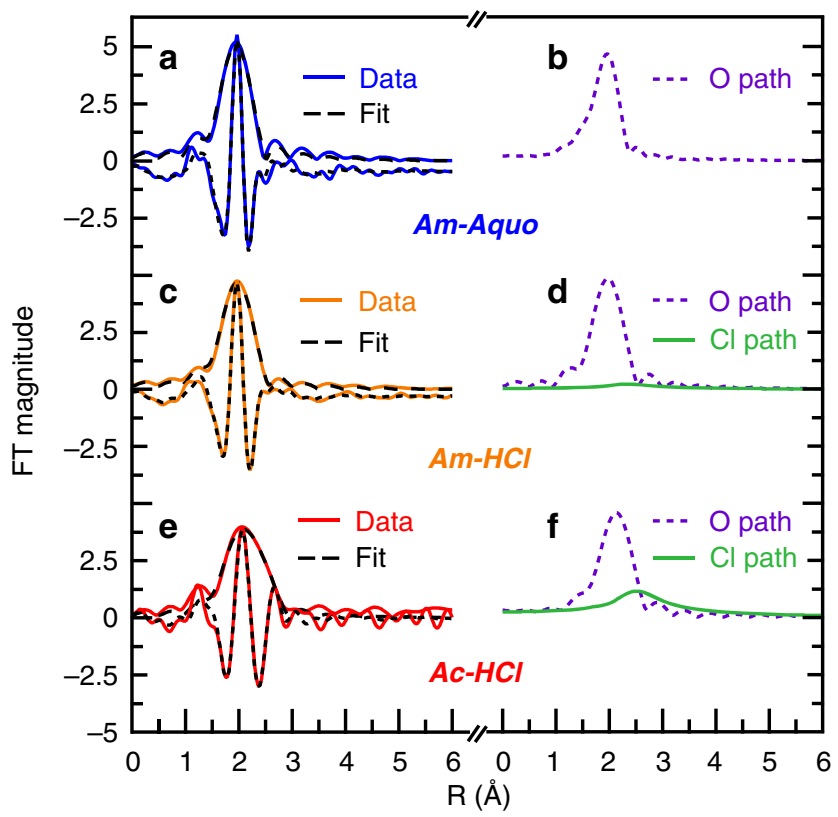

Figure 3 | Fourier Transform of the Ac'II and Am ${ }^{\prime \prime \prime} \boldsymbol{k}_{\mathbf{3}}$-EXAFS. (a) Fourier Transform of $k^{3}$-EXAFS spectra from Am-Aquo $\left(0.11 \mathrm{M} \mathrm{HO}_{3} \mathrm{SCF}_{3}\right)$ in blue trace and its fit in dashed black trace. (b) Oxygen path contribution in the fitted data in dashed purple. (c) Fourier Transform of $k^{3}$-EXAFS spectra from $\mathbf{A m}-\mathbf{H C l}(11 \mathrm{M} \mathrm{HCl})$ in red trace and its fit in dashed black trace. (d) Oxygen and chlorine paths contribution in the fitted data in dashed purple and green solid trace, respectively. (e) Fourier Transform of $k^{3}$-EXAFS spectra from $\mathbf{A c}-\mathbf{H C l}(11 \mathrm{M} \mathrm{HCl})$ in red trace and its fit in dashed black trace. (f) Oxygen and chlorine paths contribution in the fitted data in dashed purple and green solid trace, respectively.
(12.5 M) - showed $1.8 \mathrm{Cl}^{1-}$ ligands ${ }^{35}$. When experimental errors were considered, our data also agreed with measurements conducted at similar $\mathrm{Cl}^{1-}$ concentrations, for example, Allen et al. identified $1.2 \mathrm{Cl}^{1-}$ ligands in solutions containing mixtures of $\mathrm{HCl}(0.25 \mathrm{M})$ and $\mathrm{LiCl}(10.0 \mathrm{M})$ (ref. 35). Our 2.75(3) Am-Cl and $2.48(1)$ Am- $\mathrm{O}_{\mathrm{H}_{2} \mathrm{O}}$ distances also agreed with metrics from the solid-state single-crystal X-ray diffraction study, 2.799(2) and 2.462(9) $\AA$, respectively ${ }^{36}$, and were consistent with Allen et al.'s solution-phase EXAFS results in $\mathrm{LiCl}(10.0 \mathrm{M}, 12.5 \mathrm{M})$; which had Am- $\mathrm{Cl}$ distances between 2.80 and $2.81 \AA$ and $\mathrm{Am}-\mathrm{O}_{\mathrm{H}_{2} \mathrm{O}}$ distances varying from 2.48 to $2.51 \AA^{35}$.

These $\boldsymbol{A} \boldsymbol{m}-\mathbf{H C l}$ EXAFS results agreed with the MD-DFT calculations. The calculations were conducted similarly to those described above for $\boldsymbol{A m}$-Aquo, with the exception that one $\mathrm{Cl}^{1-}$ anion was included in the calculation. Over the course of $480 \mathrm{fs}$, we calculated an average of $1 \mathrm{Cl}^{1-}$ and $8.05 \pm 0.9 \mathrm{H}_{2} \mathrm{O}$ molecules within a radius of $4 \AA$ from the $A m^{\text {III }}$ ion. The average Am-Cl and $A m-\mathrm{O}_{\mathrm{H}_{2} \mathrm{O}}$ distances were quite similar to the experimental EXAFS values as shown in Fig. 4.

Given the paucity of actinium structural studies ${ }^{38,39}$, the DFT and MD-DFT calculations proved useful in guiding the interpretation of the EXAFS spectrum from $\mathbf{A c}-\mathbf{H C l}$. Atomic coordinates for the EXAFS refinement were obtained from MD-DFT calculations on $\mathrm{AcCl}_{3}\left(\mathrm{H}_{2} \mathrm{O}\right)_{5}$. The resulting EXAFS analysis identified two unique scattering paths; one associated with the $\mathrm{H}_{2} \mathrm{O}$ ligands composed of $6.6 \pm 1.8$ molecules at $2.59(3) \AA$ and a second at 2.95(3) $\AA$ consisting of $3.2 \pm 1.1$ $\mathrm{Cl}^{1-}$ ligands (Debye-Waller factor $=0.0074 \AA^{2}$; Figs 2 and 3 ). These bond distances were in excellent agreement with the sum of the $\mathrm{Ac} \mathrm{C}^{\mathrm{III}}$ and $\mathrm{Cl}^{1-}$ ionic radii, $1.12 \AA+1.81 \AA=2.93 \AA$ (ref. 40 ). If the chlorine path was ignored and only the oxygen path used, the quality of the fit decreased ( $>93 \%$ confidence based on the Hamilton's statistical test $\left.{ }^{37}\right)$, gave a high Debye-Waller 


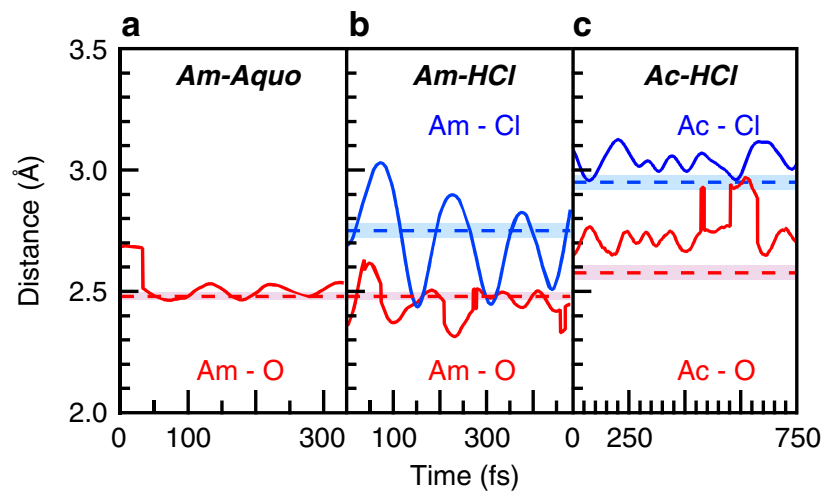

Figure 4 | MDDFT calculations. The calculated mean $\mathrm{M}-\mathrm{O}_{\mathrm{H}_{2} \mathrm{O}}$ (solid red traces) and $\mathrm{M}-\mathrm{Cl}$ (solid blue traces) distances for $\mathrm{O}$ and $\mathrm{Cl}$ atoms within $4 \AA$ of the metal ( $A m$ or $A c$ ) have been compared with the values obtained from the experimental EXAFS analyses $\left(\mathrm{M}-\mathrm{O}_{\mathrm{H}_{2} \mathrm{O}}\right.$ dashed red and $\mathrm{M}-\mathrm{Cl}$ dashed blue traces with their associated errors bars represented as shaded boxes). Experimental errors bars were 0.01 or $0.03 \AA$. See Table 1. (a) Data for Am-Aquo, (b) Data for $\mathbf{A m - H C l}$ and (c) Data for $\mathbf{A c - H C I}$.

factor value $\left(0.018 \AA^{2}\right)$, and provided an unrealistic number of coordinated $\mathrm{H}_{2} \mathrm{O}$ molecules (14 total).

The $\mathbf{A c}-\mathbf{H C l}$ experimental data agreed well with MD-DFT calculations conducted on a box containing one $\mathrm{Ac}^{\mathrm{III}}$, three $\mathrm{Cl}^{1-}$ ligands and $64 \mathrm{H}_{2} \mathrm{O}$ molecules for 1 ps. The MD-DFT revealed all three $\mathrm{Cl}^{1-}$ and $6.14 \pm 0.34 \mathrm{H}_{2} \mathrm{O}$ ligands within $4 \AA$ of the $\mathrm{Ac}^{\mathrm{III}}$ ion for the duration of the calculation. The average $\mathrm{Ac}-\mathrm{O}_{\mathrm{H}_{2} \mathrm{O}}$ and $\mathrm{Ac}-\mathrm{Cl}$ distances were calculated to be $2.76 \pm 0.08$ and $3.04 \pm 0.13 \AA$, respectively. Although the magnitudes of these values were larger than that determined experimentally (by $0.17 \AA$ for $\mathrm{Ac}-\mathrm{O}_{\mathrm{H}_{2} \mathrm{O}}$ and $0.09 \AA$ for $\left.\mathrm{Ac}-\mathrm{Cl}\right)$, the calculated and experimental results agreed within $1 \sigma$ for the $\mathrm{Ac}-\mathrm{Cl}$, and $2 \sigma$ for the $\mathrm{Ac}-\mathrm{O}_{\mathrm{H}_{2} \mathrm{O}}$. Such deviations between theory and experiment were not unusual and have been observed in calculations on other systems that employed the generalized gradient approximation functional. The calculated CNs also agreed with the experimental values, showing $\sim 3 \mathrm{Cl}^{1-}$ and $\sim 6 \mathrm{H}_{2} \mathrm{O}$ inner-sphere ligands. We note that the agreement between experiment and theory was better in the two americium cases described above. It was possible that these subtle differences between theory and experiment resulted from the low signal-to-noise at high $k$ in the experimental $\mathrm{Ac}_{3}$-edge EXAFS spectrum, as the actinium concentrations were appreciably smaller than americium $(\mu \mathrm{M}$ versus $\mathrm{mM})$. Alternatively, it was possible that the behaviour of $A c^{\text {III }}$ was more difficult to model, as the fundamentals of actinium have been less well defined than those of americium. Regardless, both theory and experiment indicated substantial differences between the $\mathrm{Ac}^{\mathrm{IfI}}$ and $\mathrm{Am}^{\mathrm{III}}$ coordination environments in $\mathrm{HCl}$ solutions, which represented an unexpected variation in actinide(III) reactivity. It is this observation that has inspired our future efforts to better understand the origin for diverging $\mathrm{Ac}^{\mathrm{III}}$ versus $\mathrm{Am}^{\mathrm{III}}$-binding preferences.

\section{Discussion}

The experimental and computational results described here represented an exciting leap forward from previous actinium coordination chemistry studies. To most effectively communicate to the reader the significance of these results, we found it instructive to summarize the previous $\mathrm{Ac}^{\mathrm{III}}$ coordination chemistry. The majority of actinium chemistry has been inferred from methodical radio-analytical and extraction studies conducted on trace-level quantities of actinium ${ }^{39,41-43}$. Although these

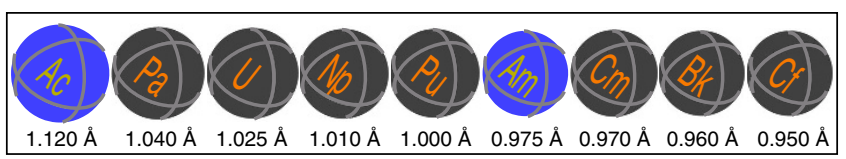

Figure 5 | Ionic radii of the early to mid-actinides. Scheme showing the ionic radii $(\AA)$ of trivalent actinides from actinium to californium drawn to scale for six-coordinate ions 40 .

previous efforts revealed differences between $\mathrm{Ac} \mathrm{c}^{\mathrm{III}}$ and the other trivalent actinide and lanthanide elements, in general, they have been interpreted as suggesting that $\mathrm{AC}$ III is a hard oxophilic tri-cation, in direct analogy to other actinide(III) cations. In addition, there have been a few studies that used macroscopic quantities of $\mathrm{Ac}$ III for analysis by ultraviolet-visible spectroscopy ${ }^{43,44}$. However, these spectra were essentially featureless-owing to the actinium $5 f^{0} \quad 6 d^{0}$ ground-state electronic configuration-and did not provide an insight into the actinium coordination environment. The majority of actinium structural data was obtained during the Manhattan project and through the years shortly after World War II. For example, Fried et al. ${ }^{38}$ and Zachariasen ${ }^{45-47}$ deduced structures and cell parameters using X-ray diffraction patterns from crystalline powders of nine actinium compounds assumed to be $\mathrm{AcF}_{3}$, $\mathrm{AcCl}_{3}, \mathrm{AcBr}_{3}, \mathrm{Ac}_{2} \mathrm{O}_{3}, \mathrm{Ac}_{2} \mathrm{~S}_{3}, \mathrm{AcOF}, \mathrm{AcOCl}, \mathrm{AcOBr}$ and $\mathrm{AcPO}_{4} \cdot \mathrm{H}_{2} \mathrm{O}$. Subsequently, Farr et al. used X-ray diffraction to characterize microgram quantities of a mixture of actinium metal and actinium hydride ${ }^{48}$. Years later, an attempt to prepare some inorganic compounds with $10 \mathrm{mg}$ of ${ }^{227} \mathrm{Ac}$ occurred. Unfortunately, radiation damage to samples and the diffraction films limited this effort to generate a single powder pattern of actinium oxalate, $\mathrm{Ac}_{2}\left(\mathrm{C}_{2} \mathrm{O}_{4}\right)_{3} \cdot 10 \mathrm{H}_{2} \mathrm{O}$ (ref. 49).

Reported here, we overcame some of the challenges associated with spectroscopic analyses of bulk actinium samples using new XAFS capabilities, which have been typically employed in tracelevel environmental science studies. Briefly, we characterized the chemistry of $\mathrm{Ac}^{\mathrm{III}}$ and $\mathrm{Am}^{\mathrm{III}}$ in concentrated $\mathrm{HCl}(11 \mathrm{M})$ solutions and compared the results with solution-phase measurements from the americium aquo ion in dilute $\mathrm{HO}_{3} \mathrm{SCF}_{3}$ $(0.11 \mathrm{M})$. Calculations involving MD-DFT, previously reported single-crystal X-ray diffraction, and previous solution-phase EXAFS results (when possible) were employed to guide our spectral interpretations. These efforts enabled the $\mathrm{Ac}-\mathrm{Cl}$ and $\mathrm{Ac}-\mathrm{O}_{\mathrm{H}_{2} \mathrm{O}}$ distances to be directly measured for the first time. Moreover, the studies revealed a substantial difference between $\mathrm{Ac}^{\mathrm{III}}$ and $\mathrm{Am}$ III solution speciation. In concentrated $\mathrm{HCl}$ solutions, we observed that $\mathrm{Ac}^{\mathrm{III}}$ and $\mathrm{Am}^{\mathrm{III}}$ were coordinated by approximately nine ligands; however, $\mathrm{Ac} \mathrm{C}^{\mathrm{III}}$ preferred approximately six $\mathrm{H}_{2} \mathrm{O}$ molecules and three $\mathrm{Cl}^{1-}$ ions, while $\mathrm{Am}^{\text {III }}$ was coordinated by approximately eight $\mathrm{H}_{2} \mathrm{O}$ and one $\mathrm{Cl}^{1-}$ ligands. It is well known that evaluating $\mathrm{CN}$ using EXAFS typically provides values with high uncertainty, $\sim 20 \%$. In spite of the large errors associated with the $\mathrm{Ac}^{\mathrm{III}}\left(\mathrm{CN}_{\mathrm{Cl}}=3.2 \pm 1.1\right)$ and $\mathrm{Am}^{\mathrm{IIP}}\left(\mathrm{CN}_{\mathrm{Cl}}=0.8 \pm 0.3\right)$ chloride $\mathrm{CNs}$, these values clearly indicated that $\mathrm{Ac}^{\mathrm{III}}$ had more $\mathrm{Cl}^{1-}$ ligands in the inner coordination sphere than $\mathrm{Am}^{\mathrm{III}}$. These results were indeed unexpected, for example, stability constants for $\mathrm{Ac}-\mathrm{Cl}$ and $\mathrm{Am}-\mathrm{Cl}$ were reported to be nearly identical ${ }^{6}$.

Perhaps differences in steric crowding accounted for the varied $\mathrm{H}_{2} \mathrm{O}$ and $\mathrm{Cl}^{1-} \mathrm{CNs}$ for the large $\mathrm{Ac}{ }^{\mathrm{III}}$ versus smaller $\mathrm{Am}{ }^{\mathrm{III}}$ ions (Fig. 5). However, Ac ${ }^{\mathrm{III}}$ electronic structure contributions may also contribute to difference in $\mathrm{H}_{2} \mathrm{O}$ versus $\mathrm{Cl}^{1-}$ binding. While the generality and origin of these results have yet to be established, they tempt us to revisit the traditional descriptions of $\mathrm{Ac}^{\mathrm{III}}$. For example, consider the possibility that $\mathrm{Ac}^{\mathrm{III}}$ is 
substantially less polarizing than the rest of the f-elements, which are well established as hard and oxophilic ions. In this sense, one might crudely compare the changes in chemical hardness from $\mathrm{Ac}^{\mathrm{III}}$ to $\mathrm{Am}^{\mathrm{III}}$ to that of iodine to fluorine. It is conceivable that a reclassification could provide insight into previous reports where actinium behaved substantially different than trivalent actinides and lanthanides ${ }^{41,42}$. Given that many Ac ${ }^{\mathrm{III}}$ chelators are based on the coordination chemistry of lanthanides and minor actinides, better characterization of the long Ac-ligand bond distances, binding preferences, and speciation has the potential to improve design parameters for actinium chelators. In this context, the results here serve as motivation for future work focused on using XAFS spectroscopy and MD-DFT calculations to advance understanding of actinium reactivity with ligands that are more relevant to $\alpha$-therapy development.

\section{Methods}

General consideration. Caution! The ${ }^{243} \mathrm{Am}$ and ${ }^{227} \mathrm{Ac}$ isotopes $\alpha-, \beta$ - and $\gamma$-emitting radionuclides have high specific activity and decay to $\alpha$-, $\beta$ - and $\gamma$-emitting isotopes. Hence, this research was conducted in a radiological facility with appropriate analyses of these hazards and implementation of controls for the safe handling and manipulation of these toxic and radioactive materials. All direct handling of these radionuclides was conducted within certified fume hoods and monitored with appropriate $\alpha$-, $\beta$ - and $\gamma$-particle detecting instruments. The ${ }^{227} \mathrm{Ac}$ and ${ }^{243} \mathrm{Am}$ isotopes were supplied by the United States Department of Energy Office of Science Isotope Program in the Office of Nuclear Physics. Hydrochloric acid and trifluoromethanesulfonic acid were obtained commercially (Fisher Scientific). Water was purified to $18.2 \mathrm{M} \Omega / \mathrm{cm}$ resistivity using ThermoScientific Barnstead Nanopure or Millipore Nanopure water purification systems. Resins used for separations-DOWEX AG1-X8 (BioRad; 100-200; Cl form) and branched DGA (Eichrom)- were suspended in water, and the fines decanted before use. Separations were characterized using $\gamma$-spectroscopy using an EG\&G Ortec Model GMX-35200-S HPGe detector system in combination with a Canberra Model 35-Plus multichannel analyser associated with Gamma Vision software. Characterization was also performed using $\alpha$-spectroscopy with and Ortec Octete $+\alpha$-spectrometer associated with Ortec Alpha Vision analytical software to control the spectrometer, to acquire and analyse the data.

Sample preparation. The coordination chemistry studies described herein made use of ${ }^{227} \mathrm{Ac}(2 \mathrm{mCi} ; 28 \mu \mathrm{g})$ and ${ }^{243} \mathrm{Am}(0.5 \mathrm{mg}$ per sample). Safety concerns regarding the radiation dose from the ${ }^{227}$ Ac sample were mitigated by removing the ${ }^{227} \mathrm{Ac}$ daughters (primarily ${ }^{227} \mathrm{Th}$ and ${ }^{223} \mathrm{Ra}$ ) the day before shipping to the SSRL synchrotron facility and by completing the measurements before significant quantities of the ${ }^{227}$ Ac daughters re-emerged, $\sim 10$ days from separation.

Given the scarcity of ${ }^{227} \mathrm{Ac}$ and ${ }^{243} \mathrm{Am}$, these actinide isotopes were recycled after the XAFS data collections. In the case of actinium, the sample matrix was converted from $\mathrm{HCl}$ to $\mathrm{HNO}_{3}(8 \mathrm{M})$ and the actinium was recovered and purified using the chromatographic procedures described below ${ }^{26,27}$. For americium, samples were recovered and purified using cation exchange chromatography ${ }^{50}$. In general, the samples were dissolved in dilute acid (five drops $\mathrm{HCl}$ in $5 \mathrm{~mL} \mathrm{H} \mathrm{H}_{2} \mathrm{O}$ ) and loaded onto a Biorad column $(10 \mathrm{ml})$ charged with AG50x8 resin $(2 \mathrm{ml})$ that had been conditioned with $\mathrm{HCl}(1 \mathrm{M} ; 5 \times 10 \mathrm{ml})$. The column was washed with $\mathrm{HCl}(0.1 \mathrm{M} ; 6 \times 10 \mathrm{ml})$, and americium was eluted from the column using concentrated $\mathrm{HCl}(12 \mathrm{M} ; 5 \times 5 \mathrm{ml})$. The recovered actinium and americium samples were analysed by $\gamma$-spectroscopy to confirm isotopic purities and the americium samples by ICP-AES to confirm chemical purities.

Actinium-227 samples. Using previously established methods ${ }^{26,27}$, radiochemical purification of ${ }^{227} \mathrm{Ac}$ was accomplished by exploiting oxidation state differences between the Ac $c^{\mathrm{III}}$ parent and the tetravalent $\left(\mathrm{Th}^{\mathrm{IV}}\right)$ and divalent $\left(\mathrm{Ra}^{\mathrm{II}}\right)$ daughters (Fig. 6). The ${ }^{227} \mathrm{Ac}$ isotope, and its daughters, were dissolved in $\mathrm{HNO}_{3}(1 \mathrm{ml} ; 8 \mathrm{M})$. The solution was loaded using $\mathrm{HNO}_{3}(4 \times 1 \mathrm{ml} ; 8 \mathrm{M})$ onto a Biorad column charged with an anionic exchange resin ( $1 \mathrm{ml}, \mathrm{AG} 1-\mathrm{X} 8$, BioRad). The resin had been conditioned with $\mathrm{H}_{2} \mathrm{O}(5 \times 3 \mathrm{ml}), \mathrm{HNO}_{3}(5 \times 3 \mathrm{ml} 8 \mathrm{M}), \mathrm{H}_{2} \mathrm{O}(1 \times 2 \mathrm{ml})$ and $\mathrm{HNO}_{3}(3 \times 3 \mathrm{ml} 8 \mathrm{M})$. Under these conditions, ${ }^{227} \mathrm{Ac},{ }^{223} \mathrm{Ra},{ }^{211} \mathrm{~Pb}$ and ${ }^{211} \mathrm{Bi}$, eluted from the column during the load and with subsequent washes with $\mathrm{HNO}_{3}$ $(10 \mathrm{ml} ; 8 \mathrm{M})$. Meanwhile ${ }^{227} \mathrm{Th}$ was retained on the resin. The eluted ${ }^{227} \mathrm{Ac}$ fractions were combined and diluted with water by a factor of two, such that the resulting solution contained $\mathrm{HNO}_{3}(4 \mathrm{M})$. The solution was loaded onto a Biorad column charged with branched DGA resin $(1 \mathrm{ml})$. The resin has been conditioned with $\mathrm{HNO}_{3}(3 \times 2 \mathrm{ml} ; 0.05 \mathrm{M})$ followed by $\mathrm{HNO}_{3}(3 \mathrm{ml} ; 4 \mathrm{M})$. Under these conditions, ${ }^{223} \mathrm{Ra}$ eluted while ${ }^{227} \mathrm{Ac}$ remained bound to the resin. The resin was washed with $\mathrm{HNO}_{3}(3 \times 2 \mathrm{ml} ; 4 \mathrm{M})$. Subsequently, ${ }^{227} \mathrm{Ac}$ was eluted using with $\mathrm{HNO}_{3}(4 \times 2 \mathrm{ml} ; 0.05 \mathrm{M})$. The ${ }^{227}$ Ac concentration was determined by

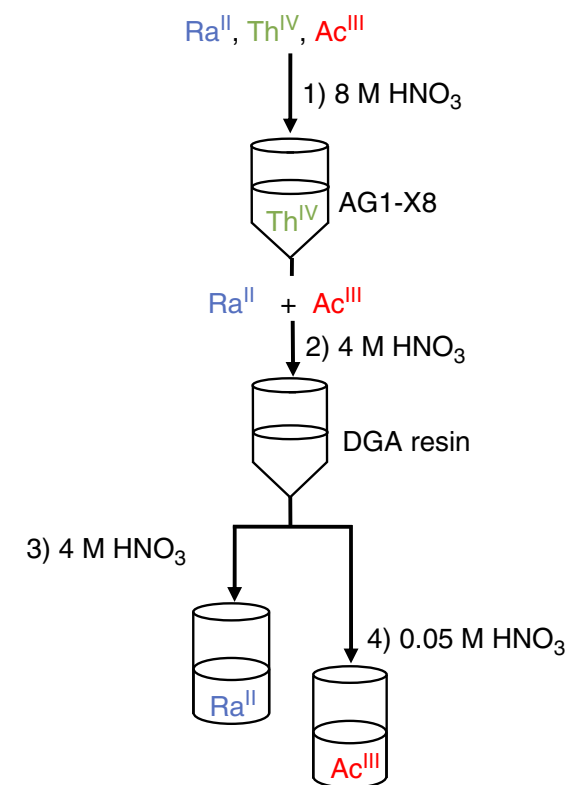

Figure 6 | Cartoon describing ${ }^{227}$ Ac radiochemical purification. Scheme showing the procedure followed to separate ${ }^{227} \mathrm{Ac}$ from its daughters ${ }^{229} \mathrm{Th}$ and ${ }^{223}$ Ra using anion exchange resin and DGA resin, respectively.

$\gamma$-spectroscopy to be highest in the first two fractions. The ${ }^{227}$ Ac fractions were combined and the solution evaporated in a conic shape glass vial on a hot plate under a slow stream of air to a soft dryness. The solid residue was converted from $\mathrm{NO}_{3}^{1-}$ to $\mathrm{Cl}^{1-}$ to generate a solution of actinium in concentrated $\mathrm{HCl}$ by repeated evaporation and dissolution in $\mathrm{HCl}(11 \mathrm{M} ; 2 \times 2 \mathrm{ml})$. The solid residue was then dissolved in $\mathrm{HCl}(0.455 \mathrm{ml} ; 11 \mathrm{M})$ and transferred to the XAFS holder.

Americium-243 samples. Americium samples in either $\mathrm{HCl}(11 \mathrm{M})$ or $\mathrm{HO}_{3} \mathrm{SCF}_{3}$ $(0.11 \mathrm{M})$ acidic solutions were prepared from a stock of $\mathrm{AmO}_{2}$ dissolved in $\mathrm{HCl}$ $(6 \mathrm{M})$. Solutions of americium in $\mathrm{HCl}(11 \mathrm{M})$ were generated in direct analogy to the method described above for actinium. Briefly, an aliquot from an ${ }^{243} \mathrm{Am}$ stock solution containing $\mathrm{Am}^{\mathrm{III}}(0.6875 \mathrm{mg})$ in $\mathrm{HCl}(0.250 \mathrm{ml} ; 6 \mathrm{M})$ was heated to dryness in a glass vial in a sand bath on a hot plate. The solid was then dissolved in concentrated $\mathrm{HCl}(0.5 \mathrm{ml} ; 11 \mathrm{M})$ and this evaporation/dissolution process was repeated two more times. The resulting solid residue was dissolved (peach colour) in $\mathrm{HCl}(0.455 \mathrm{ml} ; 11 \mathrm{M})$ and transferred to the XAFS holder.

The solution containing americium aquo ion was prepared from an aliquot of an ${ }^{243} \mathrm{Am}$ stock solution containing $\mathrm{Am}^{\mathrm{III}}(0.6875 \mathrm{mg})$ dissolved in $\mathrm{HCl}(0.250 \mathrm{ml}$; $6 \mathrm{M})$. The solvent was removed by heating the solution in a glass vial in a sand bath on a hot plate. The solid residue was then dissolved in Millipore $\mathrm{H}_{2} \mathrm{O}$ and transferred to an Eppendorf tube ( $2 \mathrm{ml}$ volume). Quickly, $\mathrm{NaOH}(0.050 \mathrm{ml} ; 2 \mathrm{M})$ was added, the solution shaken, and centrifuged for $3 \mathrm{~min}$ (6,000 r.p.m.). The supernate was decanted from the resulting pink precipitate and discarded. The solid was washed with $\mathrm{NaOH}(2 \times 0.06 \mathrm{ml} ; 10 \mathrm{mM})$ and with Millipore $\mathrm{H}_{2} \mathrm{O}$. The solid precipitate was then dissolved in trifluoromethanesulfonic acid $(0.455 \mathrm{ml}$; $0.11 \mathrm{M}$ ) and transferred to the XAFS holder.

XAFS Sample preparation. All XAFS samples were loaded into XAFS cells that were triply contained, which protected against release of radiological material during samples shipment and XAFS experiments. The XAFS holder consisted of a plastic holder body with a $2 \mathrm{~mm}$ well equipped with a set of Teflon and a Kapton windows $(1 \mathrm{mil})$. Solutions were introduced into the holder through an injection hole sealed with a gasket that was held in place by an aluminium plate. The sample cell holder was then transferred into the secondary and the tertiary container, which were best described as a set of nested aluminium holders equipped with Kapton windows (2 mil).

XAFS measurements. The XANES and EXAFS were measured at SSRL under dedicated operating conditions $(3.0 \mathrm{GeV}, 5 \%, 500 \mathrm{~mA})$ on end station 11-2. This beamline was equipped with a 26 -pole, 2 Tesla wiggler, utilized a liquid nitrogen-cooled double-crystal $\mathrm{Si}[220]$ monochromator and employed a collimating and focusing mirrors. A single energy was selected from the white beam with a liquid- $\mathrm{N}_{2}$-cooled double-crystal monochromator utilizing $\mathrm{Si}[220]$ $(\varphi=0)$ crystals. The crystals were run de-tuned by $35 \%, \sim 500 \mathrm{eV}$ above the absorption edge to eliminate higher harmonics from the monochromatic light. 
The samples were attached to the beamline 11-2 XAFS rail. The rail was equipped with three ionization chambers through which nitrogen gas was continually flowed. One chamber was positioned before the sample holder, to monitor the incident radiation $\left(I_{0}, 10 \mathrm{~cm}\right)$. The second chamber was positioned after the sample holder, such that sample transmission $\left(I_{1}, 30 \mathrm{~cm}\right)$ could be evaluated against $I_{0}$, while a third chamber $\left(I_{2}, 30 \mathrm{~cm}\right)$ positioned downstream from $I_{1}$, so that the XANES of a calibration foil could be measured in situ during the XAFS experiments against $I_{1}$. Conditions for the americium aqua ion sample was also optimized for transmission data collection. Actinium and americium solution samples in concentrated $\mathrm{HCl}$ were measured in fluorescence mode using solid-state 100-Ge element detector against the incident radiation $\left(I_{0}\right)$. Low-energy contributions to the fluorescence signal were removed using a bromine filter (three path lengths) for actinium and yttrium (three path lengths) for americium. Before measurements, dead-time correction measurements were performed at $\sim 400 \mathrm{eV}$ above the element edge of the filter. The dead time correction curve corresponds to the plot of the windowed counts of the emission line of interest versus the total of incoming counts in the solid-state detector. This procedure was performed by putting filters (Se for Ac and $\mathrm{Sr}$ for $\mathrm{Am})$ in front of the fluorescence detector.

XAFS data analysis. Data manipulation and analysis was conducted as previously described $^{51}$. First the data were dead-time corrected and calibrated to the energy of the first inflection point of the calibration foil measured in situ. The measurements were calibrated as follows. For actinium, a $\mathrm{RbCl}$ pellet was prepared by sandwiching $\mathrm{RbCl}$ diluted with $\mathrm{BN}$ to a one absorption length thickness. The energy for the first inflection point was determined in comparison with the Bi $\mathrm{L}_{\mathrm{II}}$-edge $(15,711 \mathrm{eV})$ to be $15,203.81 \mathrm{eV}$. Americium samples were calibrated to a zirconium foil at $17,998 \mathrm{eV}$. Data from the analytes were analysed by fitting a line to the pre-edge region, which remove the background from experimental data in the spectra. Then a second- to third-order polynomial fitting was chosen for the post-edge region. The difference between pre- and post-edge lines is set to unity at the first inflection point, normalizing the absorption jump to 1.0. Each of the samples were measured for several hours resulting in the collection of 25 scans for Ac and five scans for Am. Fittings using ATHENA and ARTEMIS ${ }^{52}$ were performed using crystallographic data from americium triflate ${ }^{33}$, americium trichloride hexahydrate ${ }^{36}$ and FEFF8 calculations ${ }^{32}$. The spectra were fitted using only single-scattering paths obtained from FEFF8. The adjustments of spectra were performed in different $k$ and $R$ ranges for each samples, where $R$ is the distance to the neighbouring atom; americium triflate was adjusted in $2.6<k<12 \AA^{-1}$ and $1.25<R<3 \AA$, americium in concentrated $\mathrm{HCl}$ in $2.6<k<10.5 \AA^{-1}$ and $1.1<R<3.5 \AA$ and actinium in concentrated $\mathrm{HCl}$ in $2.6<k<9 \AA^{-1}$ and $1.2<R<3.45 \AA$. For the fitting procedure, the $\mathrm{CN}$, the distance $(R)$ and the Debye-Waller factor $\left(\sigma^{2}\right)$ were allowed to vary but for the last factor a single value was chosen for both paths used for the first shell. A single value of energy shift $\left(\Delta E_{0}\right)$ was used for all scattering paths. The amplitude reduction factor $\left(S_{0}^{2}\right)$ was set at 0.9 based on initial fits.

MD-DFT calculations. The Born-Oppenheimer MD simulations in the Helmholtz ensemble (NVT) were performed using the computer code VASP (Vienna $\mathrm{Ab}$-initio Simulations Package $)^{53}$ version 5.35. In this code, the forces on the ions are calculated from the electronic structure of the whole system computed using DFT at the generalized gradient approximation level using the functional by Purdue-Burke-Enzerhof ${ }^{54}$. A simulation box of $\left(12.54 \times 12.45 \times 12.68 \AA^{3}\right)$ was used, including the metal ion $\left(\mathrm{M}^{3+}\right)$, three $\mathrm{Cl}^{1-}$ counter-ions maintained the simulation box neutral, and for solvent medium we used 64 water molecules. However, for the simulations of the single aquo ion no counter-ions were added to the system and a uniform background charge of -3 was added to keep the neutrality of the simulation box. The basis set consists in an expansion into plane-wave functions. Because of the large size of the simulation box, the $k$-space representation included only the $\Gamma$ point. The energy cutoff for the plane-wave expansion was set at $500 \mathrm{eV}$ and scalar relativistic effects were included using the PAW-PBE potentials ${ }^{55}$. Initially the metal ion and the closest neighbouring molecules and counter ions were kept frozen and the solvent plus remaining counter-ion atoms were heated up to $498 \mathrm{~K}$ to be thermalized for $1 \mathrm{ps}$. After that a $1 \mathrm{ps}$ run was done at $298 \mathrm{~K}$ with all the degrees of freedom released to thermalize the complex with the solvent. Finally a 1 ps data collection run was performed where we monitored the solvent and ion dynamics.

Data availability. The data that support the findings of this study are available within the article or from the corresponding authors on request.

\section{References}

1. McDevitt, M. R. et al. Radioimmunotherapy with alpha-emitting nuclides. Eur. J. Nucl. Med. 25, 1341-1351 (1998).

2. Steinbach, O. C. The latest developments in therapeutic delivery. Ther. Deliv 5, 113-118 (2014).

3. Parker, S. et al. Alpha emitter radium-223 and survival in metastatic prostate cancer. N. Engl. J. Med. 369, 213-223 (2013).
4. Mathur, J. N., Murali, M. S. \& Nash, K. L. Actinide partitioning-a review. Solvent Extr. Ion Exc. 19, 357-390 (2001).

5. Poinssot, C., Rostaing, C., Baron, P., Warin, D. \& Boullis, B. Main results of the French program on partitioning of minor actinides, a significant improvement towards nuclear waste reduction. Proc. Chem.y 7, 358-366 (2012).

6. Morss, L. R., Edelstein, N. M. \& Fuger, J. The Chemistry of the Actinide and Transactinide Elements (Springer, 2006).

7. Paviet-Hartmann, P., Cerefice, G., Stacey, M. R. \& Bakhtiar, S. in Proceedings of ICONE19, 19th International Conference on Nuclear Engineering (Chiba, Japan, 2011).

8. Evans, W. J. \& Kozimor, S. A. Expanding the chemistry of $\mathrm{U}^{3+}$ reducing agents. Coord. Chem. Rev. 250, 911-935 (2006).

9. Drozdzynski, J. Tervalent uranium compounds. Coord. Chem. Rev. 249, 2351-2373 (2005).

10. Knope, K. E. \& Soderholm, L. Solution and solid-state structural chemistry of actinide hydrates and their hydrolysis and condensation products. Chem. Rev. 113, 944-994 (2013).

11. Antonio, M. R., Williams, C. W. \& Soderholm, L. Berkelium redox speciation. Radiochim. Acta 90, 851-856 (2002).

12. Skanthakumar, S., Antonio, M. R., Wilson, R. E. \& Soderholm, L. The curium aqua ion. Inorg. Chem. 46, 3485-3491 (2007)

13. Polinski, M. J., Alekseev, E. V., Depmeier, W. \& Albrecht-Schmitt, T. E. Recent advances in trivalent $f$-element borate chemistry. Z. Kristallogr. 228, 489-498 (2013).

14. Cary, S. K. et al. Emergence of californium as the second transitional element in the actinide series. Nat. Commun. 6, 1-8 (2015).

15. Cross, J. N. et al. Syntheses, structures, and spectroscopic properties of plutonium and americium phosphites and the redetermination of the ionic radii of $\mathrm{Pu}(\mathrm{III})$ and $\mathrm{Am}(\mathrm{III})$. Inorg. Chem. 51, 8419-8424 (2012).

16. NSAC Isotopes Subcommittee, Meeting Isotope Needs and Capturing Opportunities for the Future: The 2015 Long Range Plan for the DOE-NP Isotope Program. (July 2015).

17. Miederer, M., Scheinberg, D. A. \& McDevitt, M. R. Realizing the potential of the actinium-225 radionuclide generator in targeted alpha particle therapy applications. Adv. Drug Deliv. Rev. 60, 1371-1382 (2008).

18. Kim, Y.-S. \& Brechbiel, M. W. An overview of targeted alpha therapy. Tumor Biol. 33, 573-590 (2012).

19. Duckworth, O. W., Bargar, J. R. \& Sposito, G. Sorption of ferric iron from ferrioxamine $B$ to synthetic and biogenic layer type manganese oxides. Geochim. Cosmochim. Acta 72, 3371-3380 (2008).

20. Lukens, W. W., Shuh, D. K., Schroeder, N. C. \& Ashley, K. R. Identification of the non-pertechnetate species in Hanford waste tanks, $\mathrm{Tc}(\mathrm{I})$-carbonyl complexes. Environ. Sci. Technol. 38, 229-233 (2004).

21. Jensen, M. P., Neuefeind, J., Beitz, J. V., Skanthakumar, S. \& Soderholm, L. Mechanisms of metal ion transfer into room-temperature ionic liquids: the role of anion exchange. J. Am. Chem. Soc. 125, 15466-15473 (2003).

22. Spezia, R., Beuchat, C., Vuilleumier, R., D’Angelo, P. \& Gagliardi, L. Unravelling the hydration structure of $\mathrm{ThX}_{4}(\mathrm{X}=\mathrm{Br}, \mathrm{Cl})$ water solutions by molecular dynamics simulations and X-ray absorption spectroscopy. J. Phys. Chem. B. 116, 6465-6475 (2012).

23. Atta-Fynn, R. et al. Structure and hydrolysis of the U(IV), U(V), and U(VI) aqua ions from ab initio molecular simulations. Inorg. Chem. 51, 3016-3024 (2012).

24. Bera, M. K. et al. Aggregation of heteropolyanions in aqueous solutions exhibiting short-range attractions and long-range repulsions. J. Phys. Chem. C 120, 1317-1327 (2016).

25. Priest, C., Tian, Z. \& Jiang, D. First-principles molecular dynamics simulation of the $\mathrm{Ca}_{2} \mathrm{UO}_{2}\left(\mathrm{CO}_{3}\right)_{3}$ complex in water. Dalton Trans. 45, 9812-9989 (2016).

26. Zielinska, B., Apostolidis, C., Bruchertseifer, F. \& Morgenstern, A. An improved method for the production of Ac-225/Bi-213 from Th-229 for targeted alpha therapy. Solvent Extr. Ion Exc. 25, 339-349 (2007).

27. Apostolidis, C., Molinet, R., Rasmussen, G. \& Morgenstern, A. Production of Ac-225 from Th-229 for targeted $\alpha$ therapy. Anal. Chem. 77, 6288-6291 (2005).

28. Teo, B. K. EXAFS: Basic Principles and Data Analysis (Springer, 1986).

29. Stohr, J. NEXAFS Spectroscopy. 25 (Springer-Verlag Berlin Heidelberg, 1992).

30. Soderholm, L., Williams, C., Skanthakumar, S., Antonio, M. R. \& Conradson, S The synthesis and characterization of the superconductor-related compound $\mathrm{Pb}_{2} \mathrm{Sr}_{2} \mathrm{AmCu}_{3} \mathrm{O}_{8}$. Z. Phys. B 101, 539-545 (1996).

31. Runde, W. H. \& Mincher, B. J. Higher oxidation states of americium: preparation, characterization and use for separations. Chem. Rev. 111, 5723-5741 (2011).

32. Ankudinov, A. L., Ravel, B., Rehr, J. J. \& Conradson, S. D. Real space multiple-scattering calculation and interpretation of X-ray absorption near-edge structure. Phys. Rev. B 58, 7565-7576 (1998). 
33. Lindqvist-Reis, P. et al. The structures and optical spectra of hydrated transplutonium ions in the solid state and in solution. Angew. Chem. Int. Ed. Engl. 46, 919-922 (2007).

34. Stumpf, T., Hennig, C., Bauer, A., Denecke, M. A. \& Fanghanel, T. An EXAFS and TRFLS study of the sorption of trivalent actinides onto smectite and kaolinite. Radiochim. Acta 92, 133-138 (2004).

35. Allen, P. G., Bucher, J. J., Shuh, D. K., Edelstein, N. M. \& Craig, I. Coordination chemistry of trivalent lanthanide and actinide ions in dilute and concentrated chloride solutions. Inorg. Chem. 39, 595-601 (2000).

36. Burns, J. H. \& Peterson, J. R. The crystal structures of americium trichloride hexahydrate and berkelium trichloride hexahydrate. Inorg. Chem. 10, 147-151 (1971).

37. Downward, L., Booth, C. H., Lukens, W. W. \& Bridges, F. A variation of the F-test for determining statistical relevance of particular parameters in EXAFS fits. AIP Conf. Proc. 882, 129-131 (2006).

38. Fried, S., Hagemann, F. \& Zachariasen, W. H. The preparation and identification of some pure actinium compounds. J. Am. Chem. Soc. 72, 771-775 (1950)

39. Kirby, H. W. \& Morss, L. R. The Chemistry of the Actinide and Transactinide Elements. Ch. 2 (Springer, Dordrecht, 2006).

40. Shannon, R. D. Revised effective ionic radii and systematic studies of interatomic distances in halides and chalcogenides. Acta Crystallogr. A32, 751-767 (1976)

41. Radchenko, V. et al. Application of ion exchange and extraction chromatography to the separation of actinium from proton-irradiated thorium metal for analytical purposes. J. Chromatogr. A 1380, 55-63 (2015).

42. Horwitz, E. P., McAlister, D. R., Bond, A. H. \& Barrans, Jr R. E. Novel extraction of chromatographic resins based on tetraalkyldiglycolamides: characterization and potential applications. Solvent Extr. Ion Exc. 23, 319-344 (2005).

43. Hagemann, F. T. in National Nuclear Energy Series, Manhattan Project Technical Section, Division 4: Plutonium Project, Vol. 14A (eds Joseph J. K. and Seaborg G. T.), 14-44 (McGraw-Hill, 1954).

44. Karalova, Z. K., Myasoedov, B. F. \& Rodionova, L. M. Spectrophotometric determination of actinium. J. Anal. Chem. 28, 942-945 (1973).

45. Zachariasen, W. H. Crystal chemical studies of the $5 f$-series of elements. I. New structure types. Acta Crystallogr. 1, 265-268 (1948).

46. Zachariasen, W. H. Crystal chemical studies of the $5 f$-series of elements. VI. The $\mathrm{Ce}_{2} \mathrm{~S}_{3}-\mathrm{Ce}_{3} \mathrm{~S}_{4}$ type of structure. Acta Crystallogr. 2, 57-60 (1949).

47. Zachariasen, W. H. Crystal chemical studies of the $5 f$-series of elements. XII. New compounds representing known structure types. Acta Crystallogr. 2, 388-390 (1949)

48. Farr, J. D., Giorgi, A. L., Bowman, M. G. \& Money, R. K. The crystal structure of actinium metal and actinium hydride. J. Inorg. Nucl. Chem. 18, 42-47 (1961).

49. Weigel, F. \& Hauske, H. The lattice constants of actinium(III) oxalate decahydrate. J. Less Common Metals 55, 243-247 (1977).

50. Stevenson, P. C. \& Nervik, W. E. The Radiochemistry of the Rare Earths, Scandium, Yttrium, and Actinium. (National Academy of Sciences National Research Council (US). Subcommittee on Radiochemistry (1961).

51. Calvin, S. XAFS for Everyone (CRC Press, 2013).

52. Ravel, B. \& Newville, M. ATHENA, ARTEMIS, HEPHAESTUS: data analysis for X-ray absorption spectroscopy using IFEFFIT. J. Synchrotron Radiat. 12, 537-541 (2005)

53. Kresse, G. \& Hafner, J. Ab initio molecular dynamics for liquid metals. J. Phys. Rev. B 47, 558-561 (1993).

54. Perdew, J. P., Burke, K. \& Ernzerhof, M. Generalized gradient approximation made simple. Phys. Rev. Lett. 77, 3865-3868 (1996).

55. Kresse, G. \& Joubert, J. From ultrasoft pseudopotentials to the projector augmented-wave method. Phys. Rev. B 59, 1758-1775 (1999).

56. Brendebach, B. et al. X-ray absorption spectroscopic study of trivalent and tetravalent actinides in solution at varying $\mathrm{pH}$ values. Radiochim. Acta 97, 701-708 (2009)
57. Kirsh, R. et al. Oxidation state and local structure of plutonium reacted with magnetite, mackinawite and chukanovite. Environ. Sci. Technol. 45, 7267-7274 (2011).

58. Marques Fernandes, M., Scheinost, A. C. \& Baeyens, B. Sorption of trivalent lanthanides and actinides onto montmorillonite: macroscopic, thermodynamic and structural evidence for ternary hydroxo and carbonato surface complexes on multiple sorption sites. Water Res. 99, 74-82 (2016).

59. Galbis, E. et al. Solving the hydratation structure of the heaviest actinide aqua ion known: the californium(III) case. Angew. Chem. Int. Ed. Engl. 122, 3899-3903 (2010).

60. Revel, R. et al. First investigation on the L edges of the ${ }^{249} \mathrm{Cf}$ aquo ion by X-ray absorption spectroscopy. Inorg. Chem. 38, 4139-4141 (1999).

\section{Acknowledgements}

The work was supported under the LANL LDRD program (JMB, ERV and JWE) and work under the Heavy Element Chemistry Program by the Division of Chemical Sciences, Geosciences and Biosciences, Office of Basic Energy Sciences, the US Department of Energy and the US Department of Energy (ERB and SAK). Portions of this work were supported by postdoctoral and graduate Fellowships from the Glenn $\mathrm{T}$. Seaborg Institute (MGF, BWS, SCES and JJW), and the Director's Postdoctoral Fellowship (HSLP and JNC). Los Alamos National Laboratory is operated by Los Alamos National Security, LLC, for the National Nuclear Security Administration of the US Department of Energy (contract DE-AC52-06NA25396). We are grateful to the United States Department of Energy, Office of Science, Isotope Development and Production for Research and Application subprogram within Office of Nuclear Physics for support and for supplying the ${ }^{227} \mathrm{Ac}$ and ${ }^{243} \mathrm{Am}$ isotopes. Use of the Stanford Synchrotron Radiation Lightsource, SLAC National Accelerator Laboratory, was supported by the US Department of Energy, Office of Science, Office of Basic Energy Sciences under Contract No. DE-AC02-76SF00515. The SSRL Structural Molecular Biology Program is supported by the DOE Office of Biological and Environmental Research, and by the National Institutes of Health, National Institute of General Medical Sciences (including P41GM103393). The contents of this publication are solely our responsibility and do not necessarily represent the official views of NIGMS or NIH.

\section{Author contributions}

E.R.B, J.W.E., S.A.K., J.M.B., J.J.W. and M.G.F. conceived and designed the experiments. M.G.F., S.A.K., J.N.C. and S.C.E.S. prepared the analysed samples. M.G.F., H.S.L.P., S.A.K., J.L.P. and B.W.S. did the XAFS measurements on samples. M.G.F. and J.L.P did the XAFS data analysis. E.R.B. performed the DFT calculations. All the authors discussed the results and wrote the paper.

\section{Additional information}

Competing financial interests: The authors declare no competing financial interests.

Reprints and permission information is available online at http://npg.nature.com/ reprintsandpermissions/

How to cite this article: Ferrier, M. et al. Spectroscopic and computational investigation of actinium coordination chemistry. Nat. Commun. 7:12312 doi: 10.1038/ncomms12312 (2016).

This work is licensed under a Creative Commons Attribution 4.0 International License. The images or other third party material in this article are included in the article's Creative Commons license, unless indicated otherwise in the credit line; if the material is not included under the Creative Commons license, users will need to obtain permission from the license holder to reproduce the material. To view a copy of this license, visit http://creativecommons.org/licenses/by/4.0/

(C) The Author(s) 2016 